\title{
Herramientas y recursos electrónicos para la traducción de la manipulación fraseológica: un estudio de caso centrado en el estudiante
}

\section{Electronic Tools and Resources for the Translation of Phraseological Manipulation: a Student-Centered Case Study}

\section{Carlos Manuel Hidalgo-Ternero}

Universidad de Málaga

cmhidalgo@uma.es

\section{Gloria CoRpas PAstor}

Universidad de Málaga

gcorpas@uma.es

Resumen: En el presente artículo se analiza un estudio de caso llevado a cabo con estudiantes de la asignatura Traducción General «BA-AB» (II) - Inglés-Español / EspañolInglés, impartida en el segundo semestre del segundo curso del Grado en Traducción e Interpretación de la Universidad de Málaga. En él, en una primera fase, se les enseñó a los estudiantes cómo sacar el máximo partido de diferentes recursos y herramientas documentales electrónicos (corpus lingüísticos, recursos lexicográficos o la web, entre otros) para la creación de equivalencias textuales en aquellos casos en los que, fruto del anisomorfismo fraseológico interlingüe, la modificación creativa de unidades 
fraseológicas (UF) en el texto origen y la ausencia de correspondencias biunívocas presentan serias dificultades para el proceso traslaticio. De esta manera, a una primera actividad formativa sobre la traducción de usos creativos de unidades fraseológicas le sucede una sesión práctica en la que los alumnos tuvieron que enfrentarse a distintos casos de manipulación en el texto origen. Con el análisis de dichos resultados se podrá vislumbrar en qué medida los distintos recursos documentales ayudan a los traductores en formación a superar el desafío de la manipulación fraseológica.

Palabras clave: estudio de caso; manipulación fraseológica; herramientas documentales electrónicas aplicadas a la traducción; español-inglés.

\begin{abstract}
This article presents a case study carried out with students of the subject Traducción General «BA-AB» (II) - Inglés-Español / Español-Inglés, taught in the first year of the Bachelor's Degree in Translation and Interpreting, at the University of Malaga. In this regard, at a first stage, students were trained on how to exploit the possibilities offered by different e-tools and resources (language corpora, lexicographic resources, or the web, inter alia) for the creation of textual equivalences in those cases where the manipulation of idioms and the absence of one-to-one phraseological correspondences may pose problems to translation. To this end, an introductory seminar on phraseological manipulation and translation was followed by a hands-on session, where trainee translators were presented with some scenarios including manipulated idioms in the source text (ST). Overall, the insights gained from analysing the results obtained will allow us to determine to what extent the different tools can help students walk the tightrope of translating phraseological manipulation.
\end{abstract}

Keywords: case study; phraseological manipulation; e-tools for translation; EnglishSpanish.

\title{
1. INTRODUCCIÓN
}

La fraseología desempeña un papel fundamental tanto en el desarrollo de la competencia traductora como en la evaluación de la calidad de las traducciones. A este respecto, tres son los principales desafíos que presentan las unidades fraseológicas (UF) en toda labor traductora: la correcta identificación y comprensión de la UF en el texto origen (TO), la selección del equivalente o estrategia de traducción adecuados, y la apropiada reproducción de la carga semántica, pragmática y discursiva de la unidad en el texto meta. El proceso traslaticio se complica más aún cuando estas unidades se presentan en el discurso modificadas de forma creativa, y en la lengua de llegada se carece de una correspondencia primaria que consiga un efecto análogo en el texto meta.

En este trabajo presentamos un estudio de caso que se ha llevado a cabo con estudiantes de la asignatura Traducción General «BA-AB» (II) - Inglés-Español /

Carlos Manuel HIDALGO-TERNERO y Gloria CORPAS PASTOR

Herramientas y recursos electrónicos para la traducción de la manipulación fraseológica...
CLINA

vol. 6-2, December 2020, 71-94

eISSN: 2444-1961

Ediciones Universidad de Salamanca - CC BY-NC-ND 
Español-Inglés, impartida en el segundo semestre del segundo curso del Grado en Traducción e Interpretación de la Universidad de Málaga. Empleamos un enfoque centrado en el estudiante con objeto de potenciar los resultados de aprendizaje obtenidos mediante esta actividad formativa, consistente en la resolución de problemas de traducción mediante diversas técnicas heurísticas. ${ }^{1}$ Asimismo, incorporamos en nuestro enfoque el uso de herramientas y recursos electrónicos en consonancia con las actuales propuestas para adaptar la formación de traductores e intérpretes a la forma de aprender de los «nativos digitales» (Tolosa Igualada y Echeverri, 2019).

En este contexto, el trabajo se estructura de la siguiente manera. En los apartados 2 y 3 se resumen los contenidos de los seminarios teóricos previos que se impartieron a los estudiantes, a modo de introducción teórica. A continuación, se describen los distintos casos con manipulación fraseológica a los que tuvieron que enfrentarse los traductores en formación (apartado 4). En los apartados siguientes se describen y analizan las estrategias de traducción y las herramientas documentales empleadas por los estudiantes (5), así como se ofrece una discusión sobre los resultados obtenidos (6). Finalmente, en el apartado 7 se desgranan las principales conclusiones extraídas del estudio y se indican líneas de investigación futura.

\section{NOCIONES BÁSICAS SOBRE MANIPULACIÓN FRASEOLÓGICA}

La primera actividad formativa consiste en la impartición de un seminario teórico a los estudiantes, en el cual se les ofrece una breve introducción a los conceptos de fraseología y manipulación fraseológica, así como su imbricación con la traducción. Con esta finalidad, se les presenta la fraseología como una parte esencial de las lenguas, cuyas unidades están presentes en todo tipo de discurso, registro o género textual.

La heterogeneidad de estructuras que se engloban bajo el término genérico de unidad fraseológica ha dificultado el establecimiento de límites, tipologías o denominaciones comúnmente aceptados por toda la comunidad científica. No abordaremos aquí de forma pormenorizada este asunto; baste indicar que para este seminario introductorio seguimos los postulados de Corpas Pastor (1996), de referencia obligada para la disciplina:

Unidades léxicas formadas por más de dos palabras gráficas en su límite inferior, cuyo límite superior se sitúa en el nivel de la oración compuesta. Dichas unidades se caracterizan por su alta frecuencia de uso, y de coaparición de sus elementos integrantes; por su institucionalización, entendida en términos de fijación y especialización semántica;

1. Sobre las ventajas de los enfoques centrados en el estudiante para la didáctica de la traducción, véase González Davies y Scott-Tennent (2005), Card (2012) o Bell y Lygo-Baker (2017), entre otros.

Carlos Manuel HIDALGO-TERNERO Y Gloria CORPAS PASTOR

Herramientas y recursos electrónicos para la traducción de la manipulación fraseológica...
CLINA

vol. 6-2, December 2020, 71-94

elSSN: 2444-1961

Ediciones Universidad de Salamanca - CC BY-NC-ND 
por su idiomaticidad y variación potenciales; así como por el grado en el cual se dan todos estos aspectos en los distintos tipos. (Corpas Pastor 1996, 20)

Como procedimiento esencial en la traducción de UF, a los estudiantes se les enseñan los pasos propuestos por Corpas Pastor (2003): identificación de la UF en texto origen, interpretación en contexto, y búsqueda y establecimiento de sus correspondencias en el plano léxico, textual y discursivo. No obstante, este proceso traslaticio se complica enormemente cuando las UF aparecen en el discurso con algún tipo de manipulación. Por manipulación fraseológica, también conocida como desautomatización fraseológica, se hace referencia a diferentes tipos de modificaciones intencionadas y fácilmente reconocibles que afectan al plano formal, semántico o discursivo de una UF, con el objetivo de conseguir determinados efectos ilocutivos o perlocutivos, tales como humor, ironía, sorpresa o persuasión, entre otros (cfr. Zuluaga 2001, Corpas Pastor 2003, Mena Martínez 2003, y Omazić 2008). Lejos de ser un fenómeno excepcional, las UF que han sufrido algún tipo de manipulación se presentan de forma ubicua en el discurso:

Wotjak (1992), por ejemplo, ha calculado entre un 30 \% y un 50 \% para el alemán. Un porcentaje similar (40 \%) deduce Corpas Pastor (1998) para las paremias en el análisis que realiza a partir de un corpus de español actual peninsular. Lo mismo se puede decir con respecto a otras lenguas como el inglés y el francés, a tenor de los resultados obtenidos por Arnaud (1993) y Moon (1998) (Corpas Pastor 2003, 319).

En este contexto, Omazić (2008, 76-77) describe de forma pormenorizada y secuencial los principales pasos en la identificación de UF manipuladas: reconocimiento de la modificación (identificando la relación léxica, estructural, semántica o conceptual subyacente); recuperación del original; comparación de la UF original y la modificación (a través del conocimiento lingüístico, el conocimiento del mundo y las inferencias cognitivas); reconocimiento de la intención comunicativa; y, finalmente, comprensión de la modificación fraseológica en sí. Estos son, por tanto, los principales pasos que deberán seguir los traductores en formación a fin de no solo detectar sino también de establecer equivalencias en el texto meta para las UF manipuladas del texto origen.

En lo que respecta a los tipos de manipulación, existen distintas clasificaciones. Corpas Pastor (2003), por un lado, distingue entre manipulación interna, cuando la alteración afecta a alguno de los elementos integrantes de la UF, y manipulación externa, cuando la UF no presenta cambios formales, sino que es el texto (o el contexto sociocultural) en el que se integra la UF lo que activa su desautomatización. Otros trabajos posteriores han revisado esta propuesta. Por ejemplo, Timofeeva (2009), por su parte, distingue entre desautomatización formal, cuando las alteraciones, adiciones o supresiones afectan a la estructura formal de la UF, desautomatización semántica, cuando la manipulación se basa en el potencial semántico de los componentes de la UF, y desautomatización discursiva, cuando la UF se inserta, de forma intencionada, en un discurso en la que no es adecuada, como, por ejemplo, cuando pertenece a una

Carlos Manuel HIDALGO-TERNERO y Gloria CORPAS PASTOR

Herramientas y recursos electrónicos para la traducción de la manipulación fraseológica...
CLINA

vol. 6-2, December 2020, 71-94

elSSN: 2444-1961

Ediciones Universidad de Salamanca - CC BY-NC-ND 
variedad diafásica distinta del registro de un discurso concreto. Asimismo, añade que entre la desautomatización formal y la semántica se produce una relación unidireccional, dado que, en la manipulación, la alteración formal implica alteración semántica, pero la alteración semántica no conlleva necesariamente modificación en la forma. En relación con esta tipología de Timofeeva, Penadés Martínez (2014) matiza dos aspectos importantes. En primer lugar, señala que la inclusión de UF pertenecientes a un registro distinto al del discurso en el que se insertan no implica necesariamente que se desautomatice la UF, sino el propio discurso, que es el que adquiere esa apariencia extraña (Penadéz Martínez 2014, 288). En segundo lugar, la autora incide asimismo en que no toda alteración formal lleva consigo inexorablemente modificación en el significado de la UF en concreto, sino que puede conllevar, por ejemplo, una interpretación específica del sentido del texto. A fin de ilustrar esta afirmación, se sirve de oraciones como «aunque la voz cantante la llevaba² Eufrasio, su esposa intervenía de vez en cuando con voz entrecortada por las lágrimas», en la que la desautomatización en la percepción de la UF llevar la voz cantante tiene como efecto poner el foco en el sujeto pospuesto, pero no cambia el significado de la propia locución (Penadéz Martínez 2014, 288).

Podemos incluir aquí una tipología adicional si tenemos en cuenta la condición intencional o no de la desautomatización. Si bien existe un amplio acuerdo en la literatura científica al respecto (Zuluaga 2001, Corpas Pastor 2003, Mena Martínez 2003, Omazić 2008 y Timofeeva 2009, entre otros) en subrayar la intencionalidad como condición sine qua non para que exista manipulación fraseológica (y esta será nuestra postura al respecto), Martí Sánchez (2015) considera que la desautomatización también puede ser inintencional, con ejemplos como *destornillarse de risa (por desternillarse de risa) o *nadar en la ambulancia (por nadar en la abundancia), dado que, a su parecer, y al igual que la intencional, esta también surge de la necesidad inconsciente del hablante de motivar aquello que, en principio, parece no motivado. A este respecto, Mellado Blanco (2020), desde una perspectiva constructivista, menciona ejemplos de contaminaciones entre varias UF (como «estar a un abrir y cerrar de ojos» y «lanzar la primera piedra y esconder la mano») para señalar que no siempre es fácil distinguir entre error y manipulación y, de hecho, "en términos construccionistas, en realidad no es relevante si se trata de un intento creativo o de un lapsus. Ambos fenómenos responden a asociaciones cognitivas entre varias construcciones y demuestran [...] que las UF son unidades cognitivas con unos perfiles formales y/o léxicos bastante difusos» (Mellado Blanco 2020, 29). En nuestro estudio, atenderemos, no obstante, a aquellos casos en lo que sí existe una intención creativa manifiesta a través del empleo de la manipulación fraseológica, con el valor pragmático de atraer la atención del receptor e incitarlo a adquirir el producto anunciado. Siguiendo la tipología de Timofeeva (2009), abordaremos, de forma concreta, escenarios con desautomatización formal (los 3 primeros casos analizados) y con desautomatización semántica (los 3 siguientes).

\section{El subrayado es nuestro.}

Carlos Manuel HIDALGO-TERNERO Y Gloria CORPAS PASTOR

Herramientas y recursos electrónicos para la traducción de la manipulación fraseológica...
CLINA

vol. 6-2, December 2020, 71-94

elSSN: 2444-1961

Ediciones Universidad de Salamanca - CC BY-NC-ND 


\section{NOCIONES BÁSICAS SOBRE DOCUMENTACIÓN ELECTRÓNICA Y RECURSOS DIGITALES}

En esta segunda actividad formativa, se les presenta a los traductores en formación una serie de herramientas electrónicas (recursos lexicográficos, corpus lingüísticos, motores de búsqueda, etc.) para la traducción de las UF manipuladas en los textos origen. Entre los recursos lexicográficos se incluyen tanto diccionarios monolingües en español (como el diccionario de la Real Academia Española ${ }^{3}$ ) y en inglés (Cambridge Dictionary ${ }^{4}$ y Lexico ${ }^{5}$ ) como bilingües (Wordreference ${ }^{6}$ y Collins ${ }^{7}$ ), entre otros. Además de las posibilidades que, por antonomasia, ofrecen estos recursos para la traducción de las UF, tales como búsqueda de las distintas acepciones y correspondencias primarias para una determinada unidad, estas herramientas también permiten la búsqueda de UF con una determinada base (por ejemplo, la base somática cabeza, en UF como sentar la cabeza, ir de cabeza, traer de cabeza...) a fin de establecer un equivalente fraseológico ad hoc cuya manipulación cree en el texto meta un efecto análogo al del texto origen, como veremos a lo largo del presente trabajo.

En esta búsqueda por establecer correspondencias fraseológicas en el texto meta, los traductores en formación tienen asimismo a su disposición un recurso documental polivalente: los corpus lingüísticos. A lo largo de la presente actividad formativa trabajamos con corpus monolingües y paralelos. Estos últimos pueden a su vez estar conformados por textos origen con sus traducciones en una lengua meta (corpus paralelos bilingües) o en varias (multilingües) (cfr. Teubert 1996, Corpas Pastor 2001, y Zanettin 2012).

En este sentido, los traductores en formación aprendieron las posibilidades que ofrece la herramienta de gestión de corpus Sketch Engine y, de forma más concreta, los corpus que en ella se incluyen, tanto paralelos (OPUS 2) como monolingües en español (esTenTen y JSI Timestamped Spanish Corpus) e inglés (enTenTen y JSI Timestamped English corpus). En lo que respecta a OPUS2, este incluye corpus paralelos que permiten búsquedas tanto bilingües como multilingües entre 40 idiomas diferentes. Por su parte, los corpus eseuTenTen (más de 17500 millones de palabras) y enTenTen (15 mil millones de palabras) pertenecen a la familia de corpus TenTen, que

3. Este recurso se encuentra disponible en la siguiente dirección URL: <https://dle.rae. $\underline{\mathrm{es} />}$

4. El diccionario Cambridge Dictionary (CD) se encuentra disponible en el siguiente enlace: $<$ https://dictionary.cambridge.orgs.

5. El diccionario Lexico, diseñado en colaboración con Oxford Dictionary, se encuentra disponible en la siguiente dirección URL: <https://www.lexico.com/>

6. El diccionario Wordreference está disponible en el siguiente enlace: <https://www.wordreference.com/>

7. El diccionario Collins se encuentra disponible en la siguiente dirección URL: <https:// www.collinsdictionary.com/es>

Carlos Manuel HIDALGO-TERNERO y Gloria CORPAS PASTOR

Herramientas y recursos electrónicos

para la traducción de la manipulación fraseológica...
CLINA

vol. 6-2, December 2020, 71-94

elSSN: 2444-1961

Ediciones Universidad de Salamanca - CC BY-NC-ND 
incluye textos seleccionados de la web. Finalmente, JSI Timestamped Spanish corpus (más de 12500 millones de palabras) y JSI Timestamped English corpus (más de 49 mil millones de palabras) proceden de textos obtenidos de los avisos de actualización (RSS feed) de artículos periodísticos (Kilgarriff et al., 2003).

Así, dentro de Sketch Engine, los estudiantes aprendieron distintas funcionalidades esenciales en la labor traductora tales como Concordance, que permite observar los ejemplos de uso de una determinada unidad léxica en contexto; Thesaurus, para encontrar sinónimos o palabras similares, y Word Sketch, que, como analizamos de forma pormenorizada en Hidalgo-Ternero (2019), permite examinar el comportamiento gramatical y colocacional de un determinado lema (por ejemplo, cabeza), a fin de poder crear equivalencias fraseológicas ad hoc para el texto meta en casos de manipulación fraseológica en el texto origen.

Finalmente, como estudiaremos a lo largo de las próximas secciones, entre otros recursos electrónicos disponibles para la traducción de la manipulación fraseológica, se encuentran asimismo los motores de búsqueda (Google, Bing, Metasearch, etc.), de gran utilidad para, por ejemplo, encontrar distintos hipónimos dentro de una determinada categoría (topónimos, zoónimos, antropónimos, etc.) cuya manipulación pueda conseguir un determinado efecto paronomástico en el texto origen. Asimismo, también se encuentran disponibles en la web distintos recursos a fin de alcanzar efectos fonoestilísticos concretos en el TO, como, por ejemplo, para crear rimas (que, en adelante, denominaremos rimadores), como, por ejemplo, Rhyme Zone, Rhymer. Rhyme Brain, etc.

\section{CASOS CON MANIPULACIÓN FRASEOLÓGICA EN EL TEXTO ORIGEN}

Una vez que los traductores en formación aprendieron los distintos recursos documentales que tienen a su disposición ante el desafío de traducir la manipulación fraseológica, tuvieron que enfrentarse a distintos casos en los que la aparición de UF manipuladas, unida a la ausencia parcial de correspondencias fraseológicas biunívocas, supuso un auténtico desafío en la labor traductora. A fin de facilitar el proceso, se les proporcionó el siguiente flujo de trabajo estructurado en una secuencia de tareas predefinidas para ser implementadas con los recursos documentales presentados, a modo de estrategias heurísticas protocolizadas:

1. Identificar la UF manipulada en el texto origen.

2. Analizar la UF en el TO y determinar qué tipo de manipulación ha sufrido y qué dos lecturas se han activado con su manipulación (la literal o la figurada, o bien las dos simultáneamente), así como el valor pragmático de dicha manipulación.

Carlos Manuel HIDALGO-TERNERO y Gloria CORPAS PASTOR Herramientas y recursos electrónicos para la traducción de la manipulación fraseológica...
CLINA

vol. 6-2, December 2020, 71-94

elSSN: 2444-1961

Ediciones Universidad de Salamanca - CC BY-NC-ND 
3. Examinar si las correspondencias primarias de esa UF en el idioma meta pueden constituir equivalentes textuales no solo porque portan la misma carga semántica, pragmática y discursiva sino también porque pueden sufrir una manipulación análoga en el texto meta.

4. Si sus correspondencias primarias no cumplen dichos criterios, intentar establecer un equivalente textual que consiga un efecto perlocutivo en el TM análogo al del TO.

A continuación, a los estudiantes se les presentaron seis casos de traducción publicitaria (resolución de problemas), que contienen distintos tipos de unidades fraseológicas manipuladas en el texto de origen. Así, por un lado, analizaremos aquellos casos que incluyen una tipología heterogénea de UF (casos 1-3), a fin de contrastarlos con aquellos que incluyen, de forma concreta, somatismos (casos 4-6), es decir, UF que contienen un lexema que hace referencia a un órgano o parte del cuerpo humano o animal (Mellado Blanco 2004). En lo que respecta a su valor pragmático, la manipulación fraseológica en todos estos casos de textos publicitarios pretende el efecto perlocutivo de atraer la atención del receptor e incitarlo a adquirir el producto anunciado, a través de un juego interpretativo de tipo inferencial (Mena Martínez y Sánchez Manzanares 2015, 69).

Con este fin, además de la propia manipulación fraseológica, diferentes efectos fonoestilísticos entran en escena tales como rima, aliteración o paronomasia, entre otros, empleados de forma ubicua en este tipo de textos publicitarios (Leigh 1994, McQuarrie y Mick 2009, Phillips y McQuarrie 2002) y que, por tanto, deberán ser tenidos en cuenta en la labor traductora. Si bien ambas estrategias (manipulación fraseológica y efecto fonoestílistico) pueden coaparecer, en la presente investigación distinguiremos aquellas propuestas de traducción que presenten algún tipo de manipulación fraseológica de aquellas que incluyan algún efecto fonoestilístico que afecte a unidades léxicas simples, a fin de poder determinar en qué medida los traductores en formación han podido establecer equivalentes fraseológicos manipulados en el texto meta.

De esta manera, a continuación, pasamos a analizar los distintos escenarios con una tipología heterogénea de UF en el texto origen, todos los cuales se corresponden con casos de desautomatización formal, siguiendo la tipología de Timofeeva (2009). El caso 1 (Figura 1) presenta el enunciado "Cheap enough to say, Phuket l'll go", en el que es posible detectar la UF fuck it, formula rutinaria con el significado de 'an offensive way of saying that you do not like, respect, or care about someone or something' (CD 2020). La manipulación interna de dicha UF hacia Phuket permite activar una doble lectura: por un lado, una interpretación literal de Phuket (Tailandia) como uno de los destinos turísticos hacia los que opera esta aerolínea y, por otro, de la UF fuck it, con la cual el texto meta podría entenderse literalmente de la siguiente manera: 'Tan barato como para decir: "a tomar por culo todo, me voy a Phuket»'; todo ello con el efecto perlocutivo de incitar al receptor a dejarlo todo y reservar un vuelo con la aerolínea anunciada.

Carlos Manuel HIDALGO-TERNERO Y Gloria CoRPAS PASTOR

Herramientas y recursos electrónicos para la traducción de la manipulación fraseológica...
CLINA

vol. 6-2, December 2020, 71-94

elSSN: 2444-1961

Ediciones Universidad de Salamanca - CC BY-NC-ND 


\section{Cheap enough to say, Phuket l'll go.}

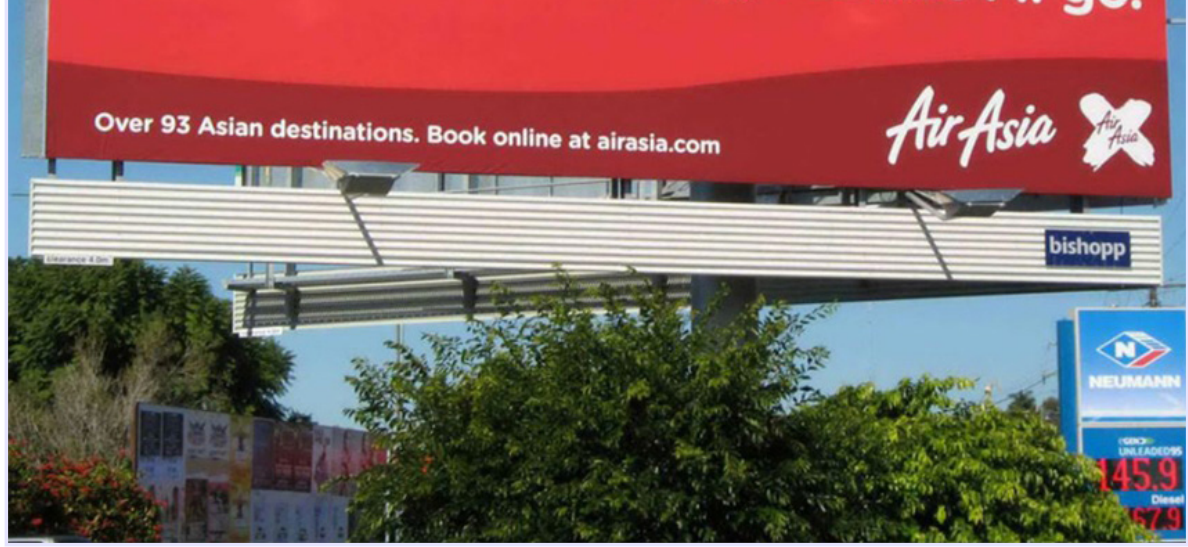

Figura 1. Caso $1^{8}$

En el caso 2 (Figura 2), es posible identificar la UF your chariot awaits, fórmula rutinaria que, en su origen, se empleaba para indicar que ya estaba preparada la carroza para transportar al receptor del mensaje y que, en la actualidad y de forma irónica, puede aplicarse para invitar el receptor a montarse en cualquier tipo de vehículo. La manipulación formal de esta UF nuevamente activa una doble interpretación tanto en ese sentido figurativo como en una nueva lectura literal con el sentido de 'tu cereza te espera', con la que se apremia al lector a adquirir la bebida del anuncio. Finalmente, en el caso 3 (Figura 3) podemos observar la UF last night, con la que se hace referencia al periodo nocturno del día inmediatamente anterior ${ }^{9}$ al del momento de habla. Su manipulación interna en la oración «Didn’t sleep last flight?» permite una doble lectura de la secuencia tanto con el sentido de last night ('anoche') como de last flight ('en el último vuelo'), con la que la compañía aérea pretende persuadir al receptor de que sus vuelos son más cómodos y placenteros que los de la competencia.

8. Imagen extraída de la siguiente dirección URL: https://www.pinterest.es/ pin/206110120418358609/

9. Por lo general, a la hora de entender la dicotomía last night/tonight los hablantes no toman como punto de referencia el momento en el que oficialmente concluye el día (las 00:00) sino que suelen usar como referente el momento en el que los interlocutores se acuestan o se levantan. Por tanto, la especificad semántica de la UF last night hace que esta deba entenderse de forma aproximada como 'el periodo nocturno inmediatamente anterior al actual periodo diurno/nocturno'.

Carlos Manuel HIDALGO-TERNERO y Gloria CORPAS PASTOR Herramientas y recursos electrónicos para la traducción de la manipulación fraseológica...
CLINA

vol. 6-2, December 2020, 71-94

elSSN: 2444-1961

Ediciones Universidad de Salamanca - CC BY-NC-ND 


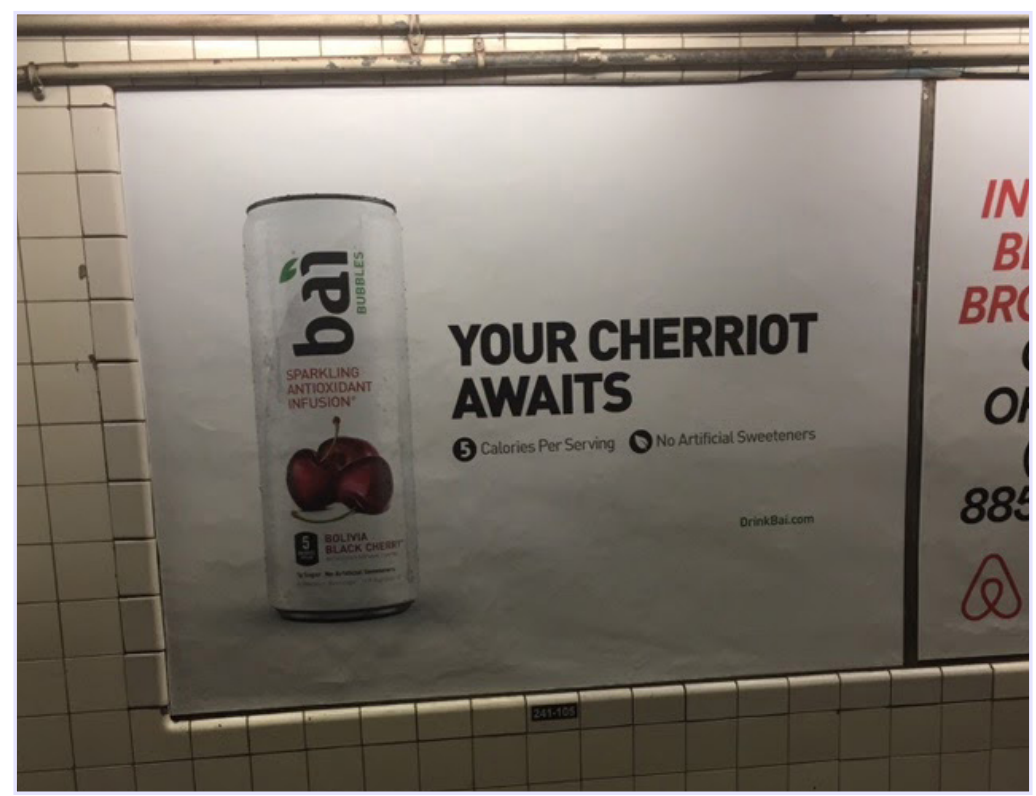

Figura 2. Caso $2^{10}$



Figura 3. Caso $3^{11}$

10. Imagen extraída de la siguiente dirección URL: https://adsonthesubway.wordpress. com/2016/05/20/why-are-we-selling-clients-work-like-this-bai-benandjerry/fullsizerender12-5/

11. Imagen extraída de la siguiente dirección URL: https://www.adsoftheworld.com/media/ print/british_airways_sleepless

Carlos Manuel HIDALGO-TERNERO y Gloria CORPAS PASTOR Herramientas y recursos electrónicos para la traducción de la manipulación fraseológica...

\section{CLINA}

vol. 6-2, December 2020, 71-94

elSSN: 2444-1961

Ediciones Universidad de Salamanca - CC BY-NC-ND 
En lo que respecta a los diferentes escenarios con somatismos en el texto meta (casos 4-6), en este caso, se corresponden con desautomatizaciones semánticas. Así, en el caso 4 (Figura 4) es posible detectar la UF comerse la cabeza, con el significado de 'pensar intensamente [en algo] u obsesionarse [con algo]' (Seco, Andrés y Ramos 2017, 179). La manipulación externa de esta secuencia activa una doble lectura tanto en su sentido figurativo ('no pienses demasiado') como en su sentido literal ('no te comas la cabeza [de la gamba]'), con la que se pretende incitar al receptor a que no se lo piense demasiado y aproveche la oferta anunciada. En el caso 5 (Figura 5), se puede identificar la UF tener cabeza (con las variantes tener la cabeza sobre los hombros [0 en su sitio]), es decir, 'razonar con sensatez y cordura' (Seco, Andrés y Ramos 2017, 110). Su manipulación externa permite también entender el TO con un sentido literal (además del fraseológico) de 'si tienes cabeza [encima de los hombros], ponte casco', por tanto, 'sí o sí, ponte casco'.

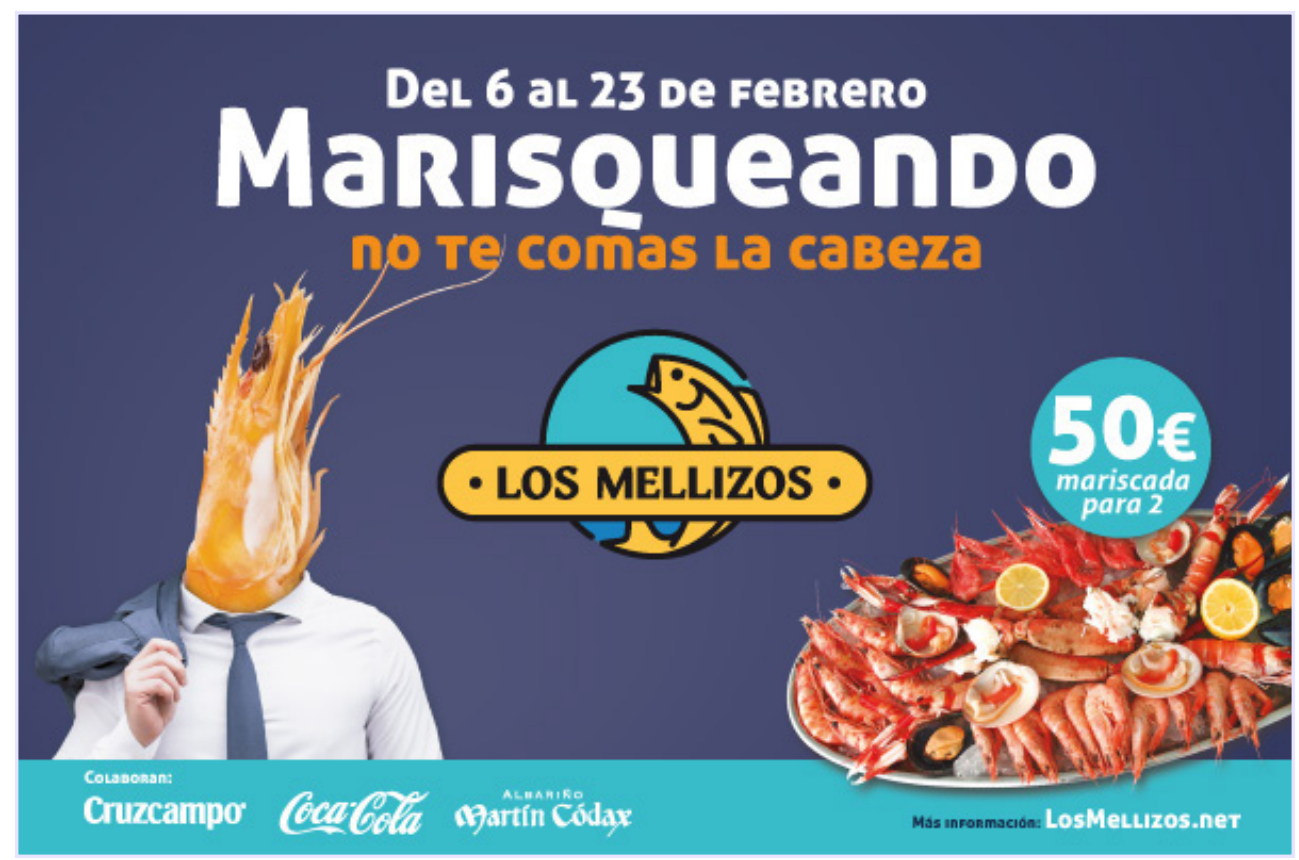

Figura 4. Caso $4^{12}$

12. Imagen extraída de la siguiente dirección URL: http://www.losmellizos.net/index. php?page=news\&id=143

Carlos Manuel HIDALGO-TERNERO y Gloria CORPAS PASTOR Herramientas y recursos electrónicos para la traducción de la manipulación fraseológica...
CLINA

vol. 6-2, December 2020, 71-94

elSSN: 2444-1961

Ediciones Universidad de Salamanca - CC BY-NC-ND 


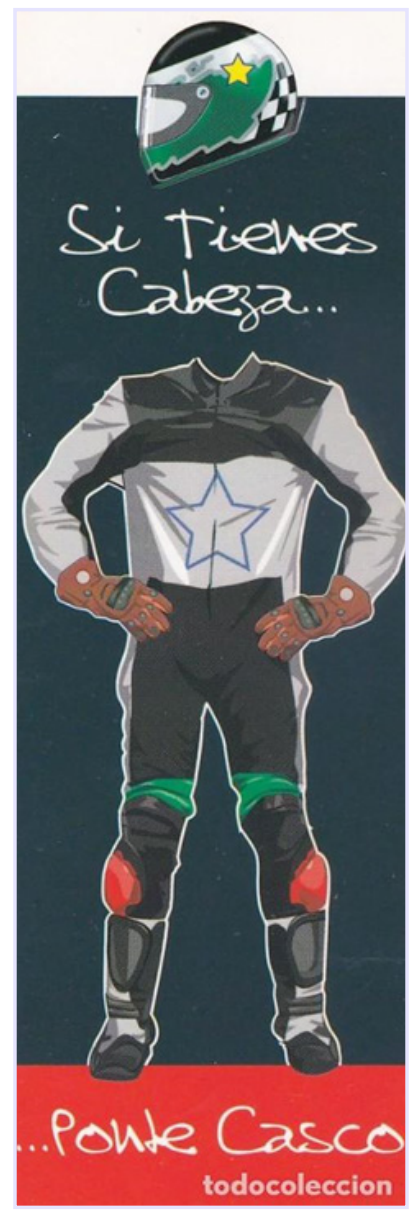

Figura 5. Caso $5^{13}$

Finalmente, en el caso 6 (Figura 6) es posible identificar la UF tener (algo) en la cabeza (con la variante tener [algo] en mente), con el significado de 'tener[lo] en el pensamiento, o pensar[lo]' (Seco, Andrés y Ramos 2017, 513). A fin de comprender la doble lectura activada con esta manipulación es necesario entender la realidad extralingüística (en Turquía se celebrarán las eliminatorias de fútbol de la Liga de Campeones de 2020) y el contexto sociocultural de la cultura origen (española): en la actualidad, son popularmente conocidos los casos de personas con alopecia que acuden a Turquía para hacerse un trasplante capilar, dado que en ese país tienen un coste menor.

13. Imagen extraída de la siguiente dirección URL: https://en.todocoleccion.net/old-bookmark/marcapaginas-si-tienes-cabeza-ponte-casco-direccion-general-trafico X133582266

Carlos Manuel HIDALGO-TERNERO Y Gloria CorPAS PASTOR

Herramientas y recursos electrónicos para la traducción de la manipulación fraseológica...

\section{CLINA}

vol. 6-2, December 2020, 71-94

elSSN: 2444-1961

Ediciones Universidad de Salamanca - CC BY-NC-ND 


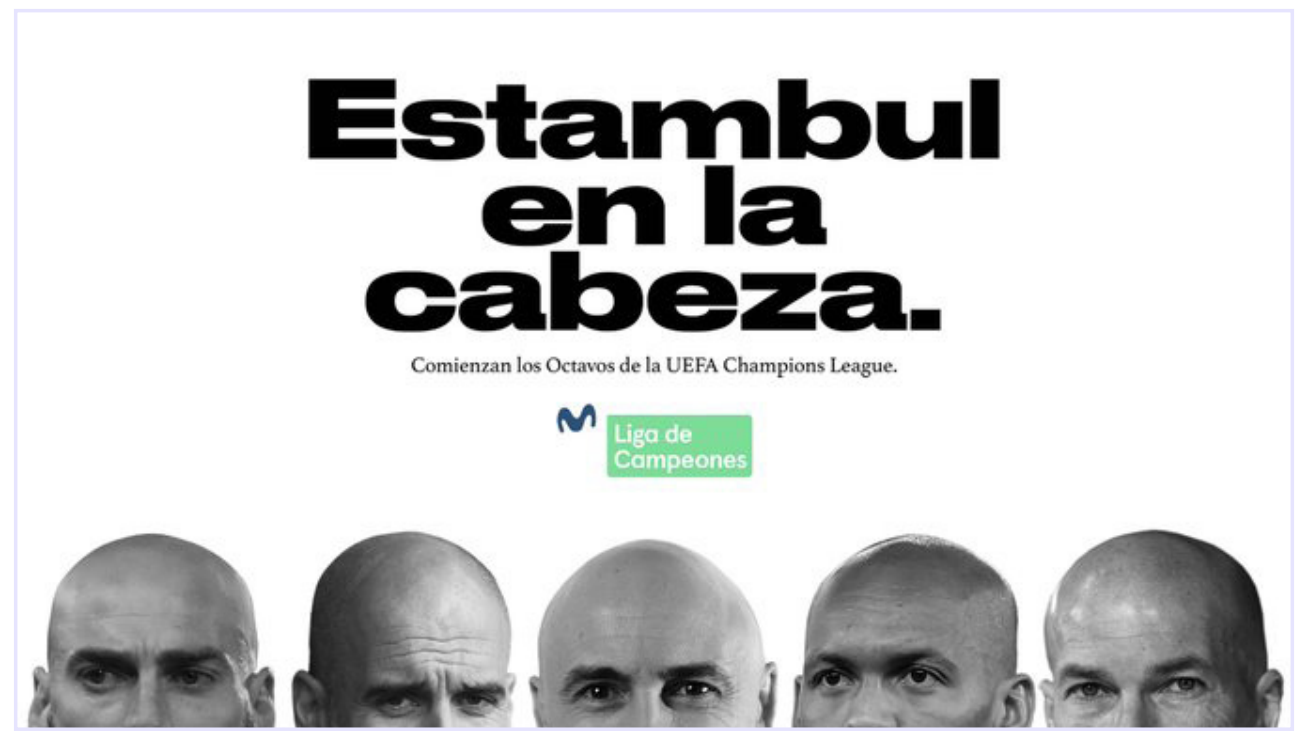

Figura 6. Caso $6^{14}$

Así, la manipulación de la UF, junto con la imagen acompañante de personas calvas famosas en el mundo futbolístico, activa una doble lectura de la oración «Con Estambul en la cabeza» tanto en el sentido de 'Pensando en Estambul [y en la Liga de Campeones]' como con el significado de 'Estambul en la cabeza [para un injerto de pelo]'; lo que pretende así conseguir el efecto perlocutivo de apremiar al receptor a que también tenga en mente ver esa competición futbolística a través del canal anunciado. Todo ello pone de relieve que, para la correcta identificación y traducción de UF manipuladas, no solo basta una alta competencia fraseológica interlingüe, sino también una conciencia plena del valor pragmático de la manipulación concreta, lo que complica enormemente la labor traductora: «la dificultad de traducción de estos usos radica, precisamente, en los factores pragmáticos que hay que considerar para su interpretación no literal, principalmente la intencionalidad del hablante y la aceptabilidad del oyente, así como el conocimiento del mundo compartido por ambos y su relación interpersonal» (Mena Martínez y Sánchez Manzanares 2015, 74).

14. Imagen extraída de la siguiente dirección URL: https://twitter.com/movistarplus/status/1229375544598331392

Carlos Manuel HidALGo-Ternero y Gloria CoRPAS PASTOR

Herramientas y recursos electrónicos para la traducción de la manipulación fraseológica...
CLINA

vol. 6-2, December 2020, 71-94

elSSN: 2444-1961

Ediciones Universidad de Salamanca - CC BY-NC-ND 


\section{RECOGIDA DE DATOS Y RESULTADOS}

Para el envío de las propuestas de traducción por parte de los 45 estudiantes participantes en el estudio, se empleó la herramienta de creación de formularios Googleform, que permite una fácil visualización y tratamiento de los resultados obtenidos. Así, con el análisis de los resultados arrojados se pretende determinar qué estrategias de traducción y qué herramientas documentales han empleado los estudiantes para cada uno de los textos origen. Por ello, los resultados que presentan diferencias morfológicas, sintácticas, léxicas u ortotipográficas se han unificado en la misma categoría siempre que se haya empleado una estrategia de traducción similar a fin de superar el desafío de la manipulación fraseológica.

Tras examinar los distintos casos, en este apartado analizamos los resultados arrojados por las diferentes propuestas realizadas por los estudiantes, con el objetivo de estudiar las estrategias de traducción y las tendencias en el uso de recursos documentales para la resolución de los problemas de traducción planteados.

Los datos relativos a los casos 1-3 arrojan resultados heterogéneos (Figura 7). En el caso 1 destaca el recurso predominante de la paronomasia en unidades léxicas simples con un $62,2 \%$ frente al $15,6 \%$ de propuestas de traducción con unidades fraseológicas manipuladas. En el extremo opuesto se encuentra el caso 3 , en el que el recurso de la manipulación fraseológica $(51,1 \%)$ predomina por encima de otros como la paronomasia o la rima, con un 4,4 \% cada una. En el caso 2, encontramos mayor homogeneidad en las propuestas de traducción, con un 31,1 \% con UF manipuladas, un $28,9 \%$ con rimas y un $24,4 \%$ con paronomasia en unidades léxicas simples.

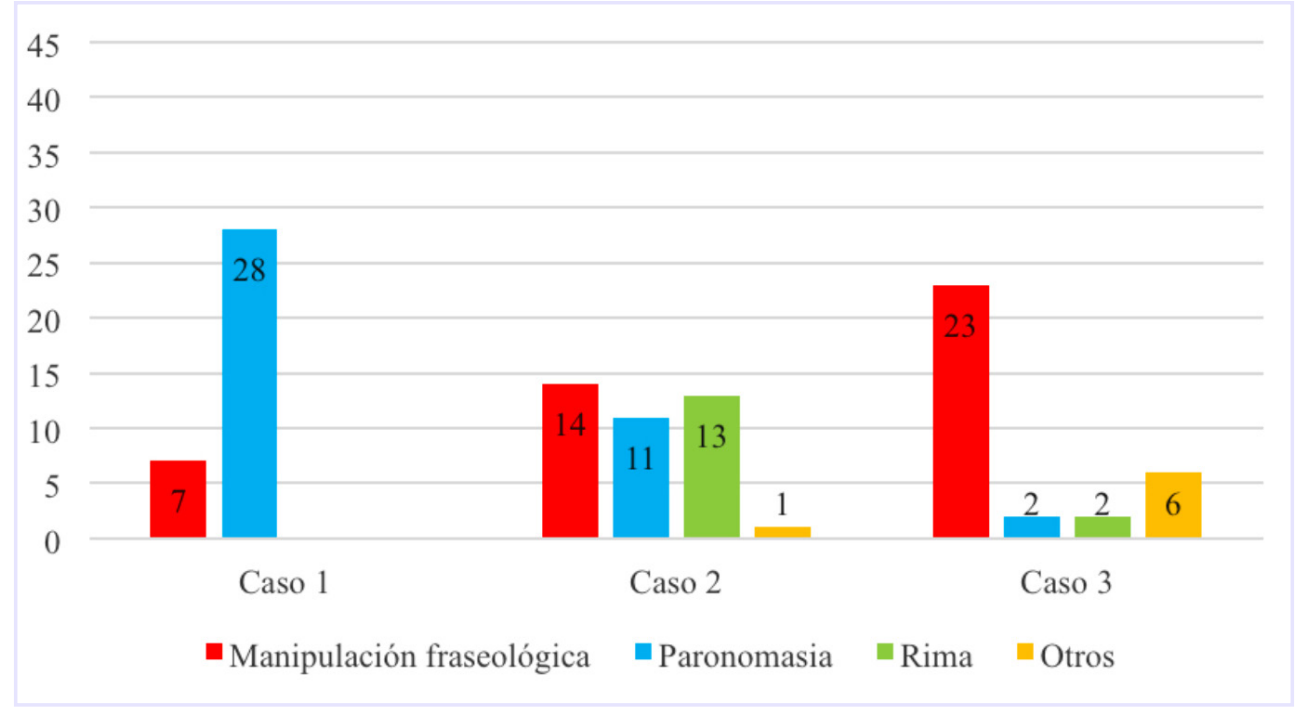

Figura 7. Casos 1,2 y 3, con otras UF

Carlos Manuel HIDALGO-TERNERO y Gloria CORPAS PASTOR Herramientas y recursos electrónicos para la traducción de la manipulación fraseológica... 
En los casos con somatismos manipulados (Figura 8), es posible observar una mayor homogeneidad en los resultados obtenidos. Así, en todos ellos destaca el uso predominante de la manipulación fraseológica, con un 73,3 \% en el caso 4, un 86,7 \% en el caso 5 , y un $73,3 \%$ en el caso 6 . Menos frecuentes resultaron la paronomasia, con un $15,6 \%$ en los casos 4 y 6 , y la rima, con un $2,2 \%$ en el caso 4 y un $6,7 \%$ en el caso 5.

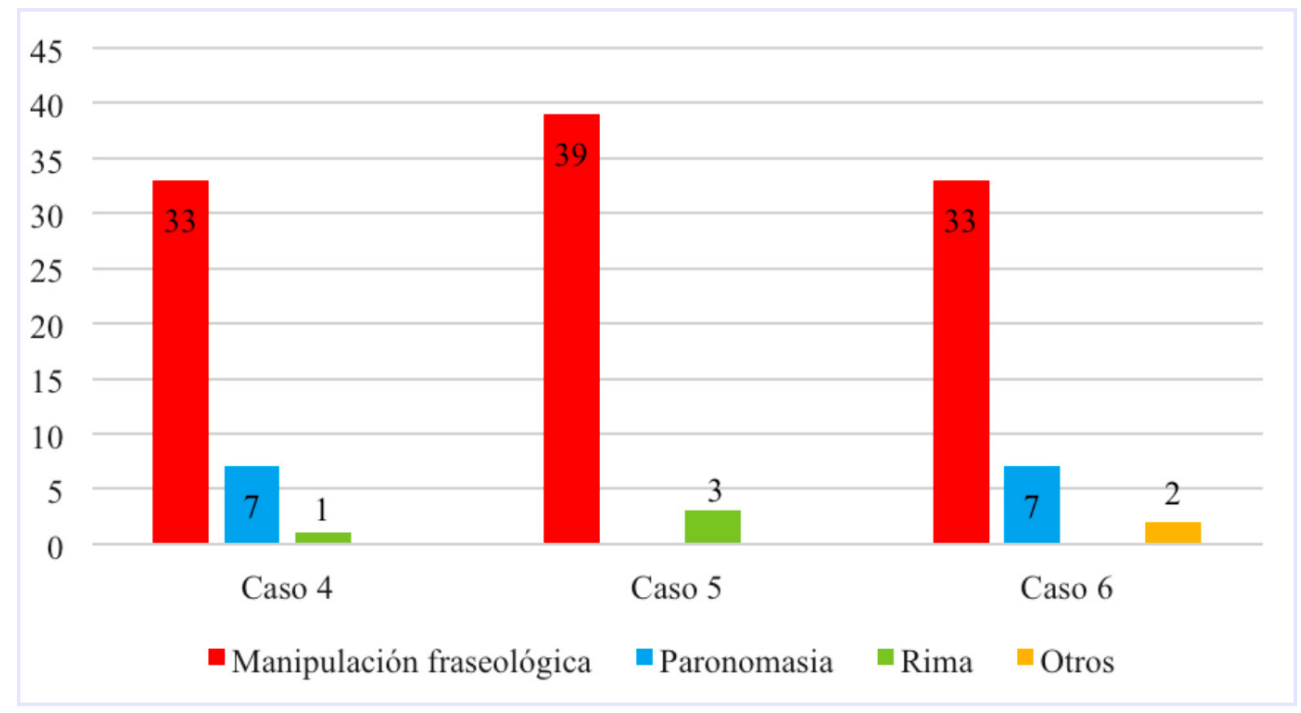

Figura 8. Casos 4, 5 y 6, con somatismos

En relación con las herramientas documentales empleadas en los casos 1-3 (Figura 9), nuevamente es posible observar aquí unos resultados bastante heterogéneos. De los 29 estudiantes que afirmaron haber hecho uso de herramientas documentales en el caso 1, 23 (es decir, un 79,3\%) emplearon los buscadores frente a 2 (6,9 \%) que emplearon los recursos lexicográficos y 4 (13,8 \%), los corpus textuales. En el caso 2, entre los 32 estudiantes que afirmaron haber utilizado alguna herramienta documental, el recurso más empleado fueron los corpus, con un 21,9\%; seguido de los rimadores, con un $25 \%$; los recursos lexicográficos, con un 21,9\%; los buscadores, con un $15,6 \%$, y, en último lugar, los traductores automáticos, con un 3,1 \%. Finalmente, en el caso 3, 16 estudiantes mencionaron haber hecho uso de los recursos documentales. De ellos, un 43,8 \% empleó los recursos lexicográficos; un $25 \%$ recurrió a los corpus y los buscadores, y un 6,2 \% hizo uso de los rimadores.

Carlos Manuel HIDALGO-TERNERO y Gloria CORPAS PASTOR Herramientas y recursos electrónicos para la traducción de la manipulación fraseológica... 


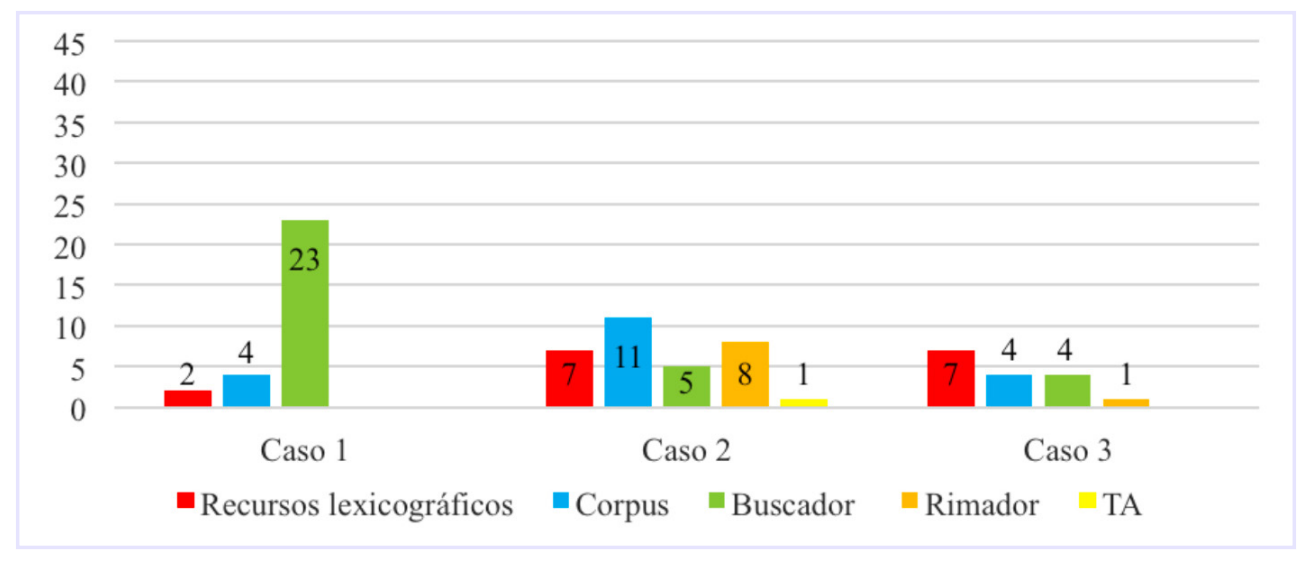

Figura 9. Herramientas documentales, con otras UF

Por otro lado, los datos para las herramientas documentales en los casos con somatismos manipulados (4-6) (Figura 10) arrojan de nuevo resultados más homogéneos que aquellos con otro tipo de unidades fraseológicas (1-3). En el caso 4, de los 27 traductores en formación que afirmaron haber empleado algún recurso documental, un $51,9 \%$ hizo uso de los recursos lexicográficos; un 44,4\%, de los corpus, y un 3,7 \%, de los buscadores. En el caso 5, 20 estudiantes recurrieron a las herramientas documentales. De ellos, un 60 \% empleó los recursos lexicográficos; un $30 \%$, los corpus, y un $10 \%$, los motores de búsqueda. Finalmente, en el caso 6 , solo dos recursos fueron empleados por los 16 traductores en formación que mencionaron haber empleado alguna herramienta: los recursos lexicográficos, con un $41,7 \%$, y los corpus, con un $58,3 \%$.

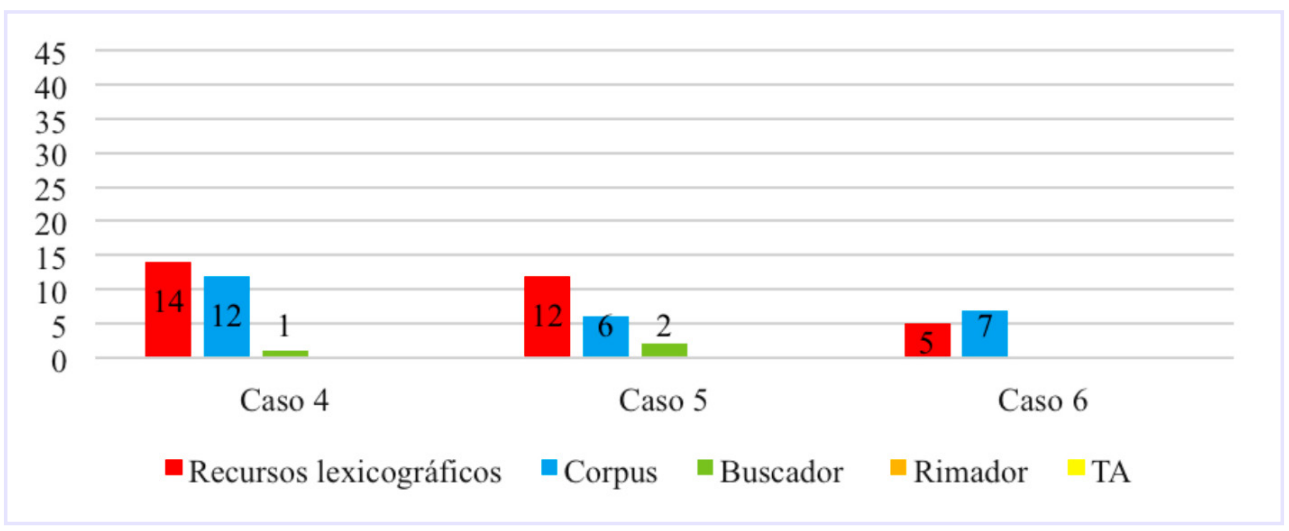

Figura 10. Herramientas documentales, con somatismos

Carlos Manuel Hidalgo-Ternero y Gloria CorPAs PAStor

Herramientas y recursos electrónicos para la traducción de la manipulación fraseológica... 
Al analizar los resultados globales con las propuestas de traducción en los casos 1-6 (Figura 11), es posible detectar un recurso mayoritario de la manipulación fraseológica $(55,2 \%)$ en el texto meta como estrategia de traducción para estos casos en los que también aparece manipulación fraseológica en el texto origen. Entre las estrategias aplicadas a unidades léxicas simples, es posible destacar la paronomasia, con un $20,4 \%$; la rima, con un $7 \%$, y otras estrategias, con un 3,3\%.

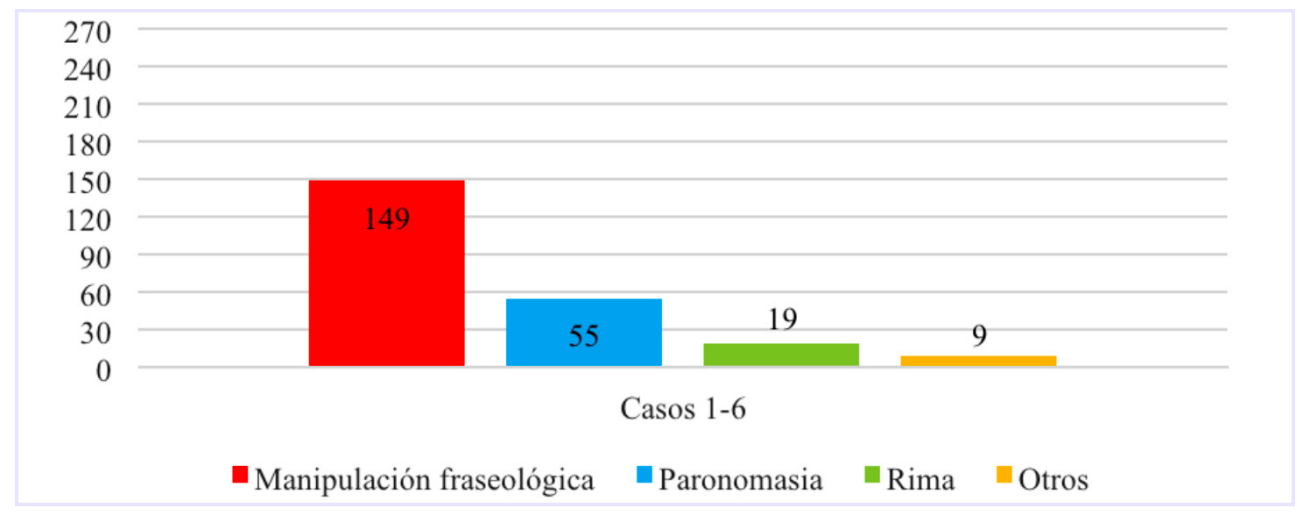

Figura 11. Casos 1-6 (resultados globales)

Con respecto a las herramientas documentales empleadas (Figura 12), los resultados globales arrojados permiten observar un uso mayoritario de los recursos lexicográficos y los corpus textuales, con unos datos cuasianálogos (34,6 \% en el caso de los recursos lexicográficos y 32,4\% para los corpus textuales). Tras ellos, destaca asimismo el empleo de los motores de búsqueda, con un $25,7 \%$, y los rimadores, con un $6,6 \%$. Finalmente, encontramos los traductores automáticos con apenas un 0,7 \% de empleo como recurso para la traducción de la manipulación fraseológica.

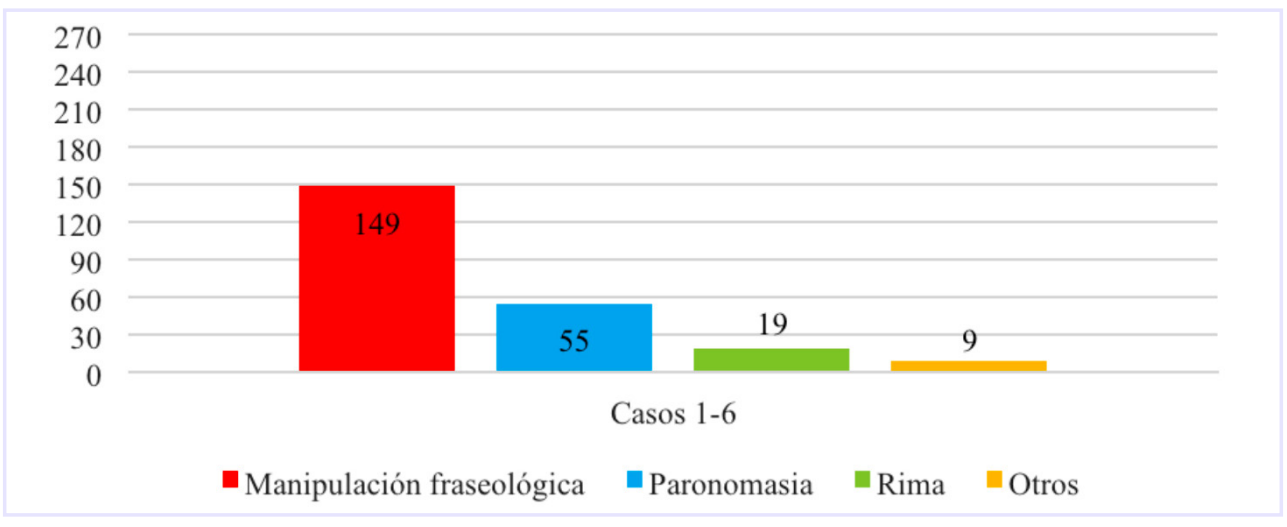

Figura 12. Herramientas documentales (resultados globales)

Carlos Manuel Hidalgo-Ternero y Gloria CorPAs PAStor

Herramientas y recursos electrónicos para la traducción de la manipulación fraseológica...
CLINA

vol. 6-2, December 2020, 71-94

elSSN: 2444-1961

Ediciones Universidad de Salamanca - CC BY-NC-ND 


\section{DISCUSIÓN}

En relación con los resultados arrojados por el estudio es posible observar que aquellos casos en los que los traductores en formación optaron por un mayor número de UF manipuladas en el texto meta se corresponden principalmente con dos tipos de escenarios. En el primer escenario, se encuentran los casos en los que las correspondencias primarias para una determinada UF en el TO comparten un análogo significado denotativo y connotativo y una misma base no solo metafórica sino también léxica que, por tanto, podía sufrir una manipulación similar a la del texto meta. Ejemplo de ello es el caso 5, en el que la UF del TO tener cabeza cuenta con una correspondencia primaria en inglés con las mencionadas características de análogo significado denotativo y connotativo y una similar base metafórica y léxica: to have a good head on one's shoulders, es decir, 'to be intelligent and able to make good decisions'. El segundo escenario lo constituyen aquellos casos en los que los traductores en formación optaron de forma mayoritaria por UF manipuladas en el TM aun no existiendo correspondencias primarias cuya manipulación pudiera activar ambas lecturas de forma análoga a la UF del TO, dado que no compartían una base léxica similar a las de las UF del TM. Los estudiantes pudieron salvar este obstáculo acudiendo al gran número de metáforas y metonimias conceptuales (Lakoff y Johnson, 1980) que comparten ambas lenguas, lo que, por tanto, permite encontrar con relativa facilidad UF en el acervo fraseológico de la lengua meta cuya manipulación pueda conseguir un efecto análogo al del TO. Por ejemplo, en el caso 3, la correspondencia primaria de la UF last night en español sería anoche, cuya manipulación no podría activar una doble lectura análoga a la del TO. Para superar esta dificultad, los estudiantes pudieron recurrir de forma preferente a otras UF sobre las que operan, por ejemplo, la metáfora orientacional FELIZ/BUENO ES ARRIBA, como podemos observar en las siguientes propuestas de traducción (con la UF subrayada):

1. Para dormir por todo lo alto

2. Que tu sueño te lleve al cielo

3. La cabezada que te llevará al séptimo cielo

4. ¿Quieres soñar que tocas el cielo?

Con estos equivalentes fraseológicos ad hoc, pudieron alcanzar en el TM un efecto perlocutivo análogo al del TO, es decir, atraer la atención del receptor y persuadirlo de las ventajas de poder dormir por todo lo alto mientras vuela con la aerolínea anunciada. Una estrategia similar se ha empleado en los casos 4, 5 y 6, en los que podemos encontrar somatismos sobre los que operan dos metonimias encadenadas:

Primeramente, la que identifica LA CABEZA con una entidad -EL CEREBRO- que se encuentra dentro de ella (metonimia LO CONTENIDO POR EL CONTENEDOR o, simplemente, LA PARTE POR EL TODO); y, en segundo lugar, la que hace corresponder el cerebro con las funciones que desempeña-generación de pensamientos, sentimientos

Carlos Manuel HIDALGO-TERNERO y Gloria CORPAS PASTOR Herramientas y recursos electrónicos para la traducción de la manipulación fraseológica...
CLINA

vol. 6-2, December 2020, 71-94 elSSN: 2444-1961

Ediciones Universidad de Salamanca - CC BY-NC-ND 
y actitudes- en la metonimia general EL INSTRUMENTO POR LA FUNCIÓN (Olza Moreno 2011, 226-227).

Estas metonimias conceptuales operantes sobre la base somática cabeza también se encuentran presentes en la lengua inglesa, lo que permite que, aunque hayan podido lexicalizar de forma distinta a lo largo del caudal fraseológico de ambas lenguas (una de las principales causas del anisomorfismo fraseológico interlingüe), los estudiantes puedan aquí también recurrir a las metáforas y metonimias conceptuales que comparten ambos sistemas a fin de crear equivalentes fraseológicos ad hoc para el texto meta. Por ejemplo, en el caso 4, una posible correspondencia primaria en inglés para la UF comerse la cabeza es to rack one's brains, es decir, 'to strain in mental effort, esp. to remember something or to find the solution to a problem' (CO 2020). No obstante, la manipulación de esta UF en inglés no podría activar una doble lectura (literal y figurada) análoga a la de la UF en español, que hiciera referencia asimismo a la imagen acompañante de la cabeza de la gamba, a través de la cual se indica de forma implícita que el receptor podrá comer marisco hasta la saciedad. Por ello, los estudiantes han optado por otras UF en la lengua meta que, aun con distinto significado denotativo y connotativo al de la UF del texto origen, sí tenían una misma base somática (head) y metonímica (LO CONTENIDO POR EL CONTENEDOR y EL INSTRUMENTO POR LA FUNCIÓN) que pudiera estar sujeta a una manipulación que consiguiese un efecto análogo para el TM. Entre estas principales UF seleccionadas para las propuestas de traducción se encuentran to lose one's head, es decir, 'to lose control and not act in a calm way' (CD 2020), o to keep one's head (also keep a cool head), con el significado de 'to stay calm despite great difficulties' (CD 2020).

Con respecto a las herramientas documentales empleadas, los resultados arrojados permiten observar un uso mayoritario de los recursos lexicográficos y los corpus textuales, con unos datos globales cuasianálogos (34,6 \% en el caso de los recursos lexicográficos y 32,4\% para los corpus textuales). En relación con las restantes herramientas, se observa una tendencia de uso acusadamente menor en los diferentes escenarios a excepción de dos casos. En el caso 1, la necesidad de encontrar topónimos o gentilicios cuya manipulación pudiera conseguir un efecto paronomástico similar al del texto origen hizo que una gran mayoría de traductores en formación realizara consultas a través de los motores de búsqueda. Así, de los 29 estudiantes que afirmaron haber hecho uso de herramientas documentales en el caso 1, 23 (es decir, un 79,3\%) emplearon los buscadores frente a 2 (6,9 \%) que recurrieron a los recursos lexicográficos y $4(13,8 \%)$, a los corpus textuales. En el caso 2 , el segundo recurso más utilizado fueron los rimadores, empleados por 8 de los 32 estudiantes que hicieron uso de recursos documentales para el caso 2 (es decir, un $25 \%$ ). Las principales consultas fueron posibles rimas para la palabra cereza a fin de, a través de un determinado juego fonoestilístico, alcanzar el efecto perlocutivo de atraer la atención del receptor y que compre el producto anunciado. Así, entre los ejemplos de textos meta con rimas podemos destacar los siguientes: Elige con certeza. Elige Bai de cereza. / Bai: Todo

Carlos Manuel HIDALGO-TERNERO Y Gloria CoRPAS PASTOR

Herramientas y recursos electrónicos para la traducción de la manipulación fraseológica...
CLINA

vol. 6-2, December 2020, 71-94 elSSN: 2444-1961

Ediciones Universidad de Salamanca - CC BY-NC-ND 
empieza con una cereza / Su té de cereza, alteza. Finalmente, los resultados muestran que la traducción automática solo fue empleada en una ocasión (0,7 \%), siendo por tanto la herramienta a la que menos se ha recurrido en la traducción de estos casos de manipulación fraseológica en el texto origen.

Los casos con manipulación de somatismos en el texto meta arrojan aún más resultados reveladores en relación con las herramientas documentales. En estos escenarios, entre los traductores en formación que han hecho uso de herramientas documentales, es posible observar un empleo casi exclusivo de los recursos lexicográficos y los corpus textuales: $51,9 \%$ y $44,4 \%$, respectivamente, en el caso $4 ; 60 \%$ y $30 \%$ en el caso 5 , y $41,7 \%$ y $58,3 \%$ en el caso 6 . El único recurso restante empleado en estos casos fueron los buscadores, de forma muy residual: 3,7 \% en el caso 4, $10 \%$ en el caso 5 y ningún uso en el caso 6 . Todo ello implica que el empleo predominante de uno u otro recurso va estrechamente ligado al tipo de manipulación fraseológica del texto origen. En aquellos casos para los que se requiera hacer búsquedas genéricas (como los distintos topónimos o gentilicios) o establecer una rima en el texto meta, los traductores en formación emplearán con preferencia los motores de búsqueda y rimadores, respectivamente. Por otro lado, en caso de necesitar crear un equivalente fraseológico ad hoc con una base concreta (como, por ejemplo, cabeza), recurrirán de forma prioritaria a los recursos lexicográficos y los corpus textuales.

Asimismo, es necesario indicar que, según los datos arrojados, la direccionalidad de traducción (EN>ES o ES>EN), por lo general, no ha sido un factor determinante ni en la estrategia de traducción predominantemente empleada ni en la herramienta documental escogida con preferencia. Así, por ejemplo, si bien se presentan distintas direccionalidades en el caso 3 (EN>ES) y en los casos 4-6 (ES>EN), en todos ellos se ha optado de forma preferente por equivalentes fraseológicos ad hoc para el texto meta, bien porque, como hemos visto, en la lengua meta existía una correspondencia primaria cuya manipulación pudo activar ambas lecturas de forma análoga a la UF del TO (caso 5), bien porque se pudo recurrir a distintas UF sobre las que operaban metáforas y metonimias conceptuales comunes a ambas lenguas (casos 3,4 y 6), sin importar la direccionalidad. Todo ello, a su vez, ha conllevado un uso predominante de los recursos lexicográficos y los corpus como herramientas documentales a fin de crear, en el texto meta, manipulaciones fraseológicas con una base concreta (como, por ejemplo, cielo o cabeza) y así poder conseguir un efecto análogo al del texto origen en ambas direccionalidades.

Finalmente, conviene señalar que nuestro estudio presenta diversas limitaciones que comprometen la generalización o extrapolación de los resultados obtenidos. En primer lugar, el número de casos analizados es discreto (solo 6) y de naturaleza heterogénea, por la direccionalidad de la traducción (1-3 de inglés a español y 4-6 de español a inglés), y la diversidad de sus respectivas bases léxicas (1-3 sin somatismos y 4-6 con somatismos). Si bien, por lo general, no se detectan diferencias acusadas en cuanto a las opciones de traducción (estrategias) empleadas por los estudiantes en la resolución de estos problemas de traducción, ni tampoco difieren esencialmente 
respecto a las tendencias de uso de recursos más frecuentes, sí se observan algunas diferencias en los casos 1-3 frente a los casos 4-6 que quizá pudieran ser atribuibles al efecto de algunas de las variables señaladas más arriba. Se hace necesario, pues, aumentar el número de problemas de traducción con UF manipuladas, así como el número de estudiantes participantes para poder confirmar las tendencias observadas y comprobar si las notas discordantes sobre uso de buscadores, rimadores, o sistemas de traducción automática, por ejemplo, pudieran obedecer a otros aspectos no analizados en detalle en este trabajo preliminar.

\section{CONCLUSIONES}

Las unidades fraseológicas manipuladas constituyen una perfecta simbiosis en la que dos lecturas (la literal y la figurada) están, al mismo tiempo, presentes y ocultas; con la sutilidad precisa para que ninguna de ellas pase desapercibida al receptor. Es por ello por lo que traducir la manipulación fraseológica es traducir, al menos, dos veces.

Estas digresiones, unidas al anisomorfismo fraseológico entre las distintas lenguas, no deben suponer un obstáculo en la labor traductora, sino que deben servir para poner en el centro a un traductor que tendrá ahora que (trans)crear una pieza paralela en el texto meta que sea capaz de alcanzar un efecto perlocutivo similar al del texto origen. Para ello, tiene a su disposición diferentes herramientas, cuya mayor o menor utilidad dependerá de la estrategia adoptada ante cada desafío traductológico. Así, en el caso de decantarse por alcanzar un determinado efecto fonoestilístico en el texto meta, recurrirá de forma preferente a los motores de búsqueda (para la paronomasia) y a los rimadores (para la rima). En caso de optar, de forma concreta, por la manipulación fraseológica, hará un uso predominante de los recursos lexicográficos y las herramientas de corpus, a fin de crear un equivalente fraseológico ad hoc cuya manipulación active ambas lecturas (la literal y la figurada) y consiga un efecto análogo al texto origen.

A tenor de los resultados obtenidos, en ulteriores investigaciones pretendemos aumentar el número de casos y variables analizadas, así como el número de participantes y el número de herramientas documentales objeto de estudio a fin de analizar, asimismo, las posibilidades que ofrecen, de forma específica, distintos recursos fraseográficos electrónicos disponibles para el español (Corpas Pastor, Hidalgo-Ternero y Bautista Zambrana 2020, Mogorrón Huerta 2012, Penadés Martínez 2015 y 2019; Sevilla Muñoz y Zurdo Ruiz-Ayúcar 2009, entre otros) ante el desafío de traducir la manipulación fraseológica.

Por último, a la luz de los resultados arrojados por el estudio, es necesario asimismo incidir en el hecho de que una enseñanza holística de los distintos recursos documentales aplicados a la traducción debe inexorablemente venir acompañada de para qué pueden ser de mayor utilidad según la estrategia de traducción que se quiera

Carlos Manuel HIDALGO-TERNERO y Gloria CORPAS PASTOR Herramientas y recursos electrónicos para la traducción de la manipulación fraseológica...
CLINA

vol. 6-2, December 2020, 71-94

eISSN: 2444-1961

Ediciones Universidad de Salamanca - CC BY-NC-ND 
adoptar, a fin de que los estudiantes puedan conseguir sacar el máximo partido de todas las posibilidades que ofrecen estas herramientas y así evitar que el desafío de traducir la manipulación fraseológica los deje sin palabras.

\section{AGRADECIMIENTOS}

La presente investigación se ha llevado a cabo en el marco de distintos proyectos de investigación en tecnologías de la lengua aplicadas a la traducción e interpretación (ref. FFI2016-75831-P, UMA18-FEDERJA-067, CEI-RIS3 y EUIN2017-87746). Asimismo, ha sido subvencionado por el Ministerio de Ciencia, Innovación y Universidades (FPU16/02032).

\section{REFERENCIAS BIBLIOGRÁFICAS}

BeLL, Lucy y Simon LYGo-BAKER. 2017. "Student-centred learning: a small-scale study of a peer-learning experience in undergraduate translation classes». The Language Learning Journal 47 (3): 299-312.

CD - Cambridge University Press. 2020. Cambridge dictionary, Cambridge Dictionary online. Fecha de acceso 19/06/2020. <https://dictionary.cambridge.org/>

CO - HarperCollins Publishers. 2020. Collins dictionary. Fecha de acceso 05/07/2020. <https:// www.collinsdictionary.com/>

CARD, Lorin. 2012. «A Foray into Student-Centered Learning (SCL): Two SCL Activities Designed to Enhance Translation Pedagogy». Translation Journal 16 (4). Fecha de acceso 23/12/2020. https://translationjournal.net/journal/62learning.htm.

CoRPAS PASToR, Gloria. 1996. Manual de fraseología española. Madrid: Gredos.

CoRPAS PASTOR, Gloria. 2001. "Compilación de un corpus ad hoc para la enseñanza de la traducción inversa especializada». Trans: Revista de Traductología 5: 155-184.

Corpas Pastor, Gloria. 2003. Diez años de investigación en fraseología: análisis sintáctico-semánticos, contrastivos y traductológicos. Madrid: Vervuert.

Corpas Pastor, Gloria, Carlos Manuel Hidalgo-Ternero y María del Rosario Bautista Zambrana. 2020. «Teaching idioms for translation purposes: a trilingual corpus-based glossary applied to Phraseodidactics (ES/EN/DE)». En Teaching Phraseology in the XXI Century: New Challenges, ed. por Flor Mena Martínez y Carola Strohschen. Berlín: Peter Lang, 75-93.

GonzÁLeZ DavieS, Maria y Christopher Scott-TenNent. 2005. «A Problem-Solving and Student-Centred Approach to the Translation of Cultural References». Meta 50 (1): 160-179.

HidAlgo-Ternero, Carlos Manuel. 2019. «Translating manipulated idioms (EN>ES) in the Word Sketch scenario». En Computational and Corpus-Based Phraseology, ed. por Gloria Corpas Pastor y Ruslan Mitkov. Cham: Springer Nature Switzerland, 173-186. DOI: https://doi. org/10.1007/978-3-030-30135-4_13

KilgarRifF, Adam, Vít Baisa, Jan Bušta, Miloš JakubičEK, Vojtěch Kowäř, Jan Michelfeit, Pavel RYCHLÝ y Vít Suchomel. 2003. The Sketch Engine. Fecha de acceso 15/07/2020. <http://www. sketchengine.co.uk>

Carlos Manuel HIDALGo-Ternero y Gloria CoRPAS PASTOR Herramientas y recursos electrónicos para la traducción de la manipulación fraseológica...
CLINA

vol. 6-2, December 2020, 71-94

elSSN: 2444-1961

Ediciones Universidad de Salamanca - CC BY-NC-ND 
LAKOFF, George y Mark JoHnson. 1980. Metaphors we live by. Chicago: University of Chicago Press.

LEIGH, James H. 1994. "The Use of Figures of Speech in Print Ad Headlines». Journal of Advertising 23 (2): 17-33. DOI: 10.1080/00913367.1994.10673439

MARTí SánCHEZ, Manuel. 2015. «La búsqueda de sentido en la desautomatización fraseológica». En Fraseología, Didáctica y Traducción, ed. por Pedro Mogorrón y Fernando Navarro Domínguez. Frankfurt am Main: Peter Lang, 117-135.

McQuaRRIE, Edward F. y David G. Mıck. 2009. «A laboratory study of the effect of verbal rhetoric versus repetition when consumers are not directed to process advertising". International Journal of Advertising 28 (2): 287-312. DOI: 10.2501/S0265048709200576

MD - Springer Nature Limited. McMillan Dictionary. Fecha de acceso 12/06/2020. <https:// www. macmillandictionary.com>

Mellado Blanco, Carmen. 2004. Fraseologismos somáticos del alemán. Frankfurt am Main: Peter Lang.

Mellado Blanco, Carmen. 2020. «La desautomatización desde el prisma de la Gramática de Construcciones: un nuevo paradigma de la variabilidad fraseológica». Nasledje 45: 17-34.

Mena Martínez, Flor. 2003. «En torno al concepto de desautomatización fraseológica: aspectos básicos». Tonos, Revista Electrónica de Estudios Filológicos 5. Fecha de acceso 04/07/2020. http://www.tonosdigital.es/ojs/index.php/tonos/article/view/516

Mena Martínez, Flor y Carmen Sánchez Manzanares. 2015. «Los usos creativos de las UF: implicaciones para su traducción inglés-español». En Enfoques actuales para la traducción fraseológica y paremiológica, ed. por Germán Conde Tarrío, Pedro Mogorrón Huerta, Manuel Martí Sánchez y David Prieto García-Seco. Madrid: Instituto Cervantes (Centro Virtual Cervantes), 59-76.

Mogorrón Huerta, Pedro. 2012. «Explotación informática de una base de datos multilingüe de unidades fraseológicas». En Unidades fraseológicas y T/C, ed. por María Isabel González Rey. Madrid: Instituto Cervantes (Centro Virtual Cervantes), 63-80.

Olza Moreno, Inés. 2011. Corporalidad y lenguaje: La fraseología somática metalingüística del español. Frankfurt am Main: Peter Lang, Studien zur romanischen Sprachwissenschaft und interkulturellen Kommunikation, Band 73. ISBN: 978-3-631-60907-1

Omazlć, Marija. 2008. «Processing of idioms and idiom modifications: A view from cognitive linguistics». En Phraseology: An Interdisciplinary Perspective, ed. por Sylviane Granger y Fanny Meunier. Amsterdam y Philadelphia: John Benjamins, 67-79.

Penadés Martínez, Inmaculada. 2014. «Fixación estrutural e desautomatización das locucións». Cadernos de Fraseoloxía Galega 16: 273-301.

Penadés Martínez, Inmaculada. 2015. Para un diccionario de locuciones. De la lingüística teórica a la fraseografía práctica. Alcalá de Henares: Servicio de Publicaciones de la Universidad de Alcalá.

Penadés Martínez, Inmaculada (ed.). 2019. Diccionario de locuciones idiomáticas del español actual. http://www. diccionariodilea.es.

PHILLIPS, Barbara J. y Edward F. McQuARRIE. 2002. "The development, change, and transformation of rhetorical style in magazine advertisements 1954-1999». Journal of Advertising 31(4): 1-13.

Seco, Manuel, Olimpia Andrés y Gabino Ramos. 2017. Diccionario fraseológico documentado del español actual, locuciones y modismos españoles (2a edición). Madrid: Aguilar.

Carlos Manuel HIDALGO-TERNERO y Gloria CORPAS PASTOR Herramientas y recursos electrónicos para la traducción de la manipulación fraseológica...
CLINA

vol. 6-2, December 2020, 71-94

elSSN: 2444-1961

Ediciones Universidad de Salamanca - CC BY-NC-ND 
SeVIlla Muñoz, Julia y María I. Teresa Zurdo Ruiz-Ayúcar [dir.]. 2009. «Refranero multilingüe». Madrid: Instituto Cervantes (Centro Virtual Cervantes). http://cvc.cervantes.es/lengua/refranero/

TEUBERT, Wolfgang. 1996. «Comparable or Parallel Corpora?». International Journal of Lexicography 9 (3): 238-264.

TIMOFEEVA, Larissa. 2009. "La desautomatización fraseológica: un recurso para crear y divertir». En Estudios de Lingüística: Investigaciones lingüísticas del siglo XXI, ed. por Juan Luis Jiménez Ruiz y Larissa Timofeeva. Alicante: Universidad de Alicante, 249-271.

Tolosa lgualada, Miguel y Álvaro EcheVerRI. 2019. «Because something should change. Translator and interpreter training: Past, present and future». En Because something should change: Present \& Future Training of Translators and Interpreters, ed. por Miguel Tolosa Igualada y Álvaro Echeverri. MonTI 11: 29-46.

Zanettin, Federico. 2012. Translation-driven corpora: corpus resources for descriptive and applied translation studies. Londres: Routledge.

Zuluaga, Alberto. 2001. «Análisis y traducción de las UF desautomatizadas». PhiN, Philologie im Netz 16: 67-83. Fecha de acceso 11/06/2020. http://web.fu-berlin.de/phin/phin16/p16t5. htm 